\title{
Analysis of Spring Flow Change in the Jinan City under Influences of Recent Human Activities
}

\author{
Xiaomeng Liu ${ }^{1,2,3}$, Litang $\mathbf{H u}^{1,2,3}$, and Kangning Sun ${ }^{1,2,3}$ \\ ${ }^{1}$ College of Water Sciences, Beijing Normal University, Beijing 100875, P.R. China \\ ${ }^{2}$ Beijing Key Laboratory of Urban Hydrological Cycle and Sponge City Technology, \\ Beijing 100875, P.R. China \\ ${ }^{3}$ Engineering Research Center of Groundwater Pollution Control and Remediation of Ministry of Education, \\ Beijing Normal University, Beijing 100875, P.R. China
}

Correspondence: Litang Hu (litanghu@bnu.edu.cn)

Received: 29 December 2017 - Revised: 9 May 2018 - Accepted: 23 May 2018 - Published: 5 June 2018

\begin{abstract}
Jinan city, the capital of Shandong Province in China, is famous for its beautiful springs. With the rapid development of the economy in recent years, water demand in Jinan city has been increasing rapidly. The over-exploitation of groundwater has caused a decline in groundwater level and, notably, dried up springs under extreme climate conditions. To keep the springs gushing perennially and sustainably use groundwater resources, the local government has implemented many measures to restore the water table, such as the Sponge City Construction Project in Jinan. Focusing on changes in spring flow and its impact factors in Jinan, this paper analyzes the changes in observed spring flow in the most recent 50 years and then discusses the causes of decreases in the spring flow with the consideration of climate and human activities. Spring flow in the study area was changed from the natural state to a period of multiwater source management. The artificial neural network (ANN) model was developed to demonstrate the relationship among spring flow, precipitation, and groundwater abstraction to predict the variations of spring flow under the conditions of climate change and human activities. The good agreement between the simulated and observed results indicates that both precipitation and exploitation are important influence factors. However the effective infiltration of precipitation into groundwater is the most influential factor. The results can provide guidance for groundwater resource protection in the Jinan spring catchment.
\end{abstract}

\section{Introduction}

Covering an area of approximately $7-12 \%$ of the earth's land area, karst regions are an important part of the planet, with karst aquifers supplying more than $25 \%$ of the drinking water for the world's population. Karst water is an indispensable water source for the world (Vries and Simmers, 2002; Bakalowicz, 2005; Hartmann et al., 2014). In northern China, there are abundant karst catchments in Shanxi, Shandong, Henan, and Hebei provinces, where karst aquifers also supply the major water resources for domestic, municipal and industrial uses and agricultural irrigation. The karst systems in these areas are dominated by fissures, fractures and conduits, which provide extensive storage for precipitation and enough water resources for karst springs (Ma et al., 2004; Qian et al., 2006; Hu et al., 2008; Kang et al., 2011).

Jinan is the provincial capital of Shandong province in China and is famous for numerous karst springs, such as Baotu springs and Heihu springs. According to the Jinan Statistical Yearbook, Jinan's gross domestic product (GDP) was approximately CNY 9.83 billion (USD 1.552 billion) in 1988, then reached CNY 95.22 billion (USD 15.04 billion) in 2000, and reached CNY 610.02 billion (USD 96.33 billion) in 2015, thus increasing more than 62 times in 27 years. As a result of the rapid development of the economy, water demand quickly increased, resulting in an increase in groundwater abstraction. The over-exploitation of groundwater in Jinan has caused many problems, such as the decline of the 


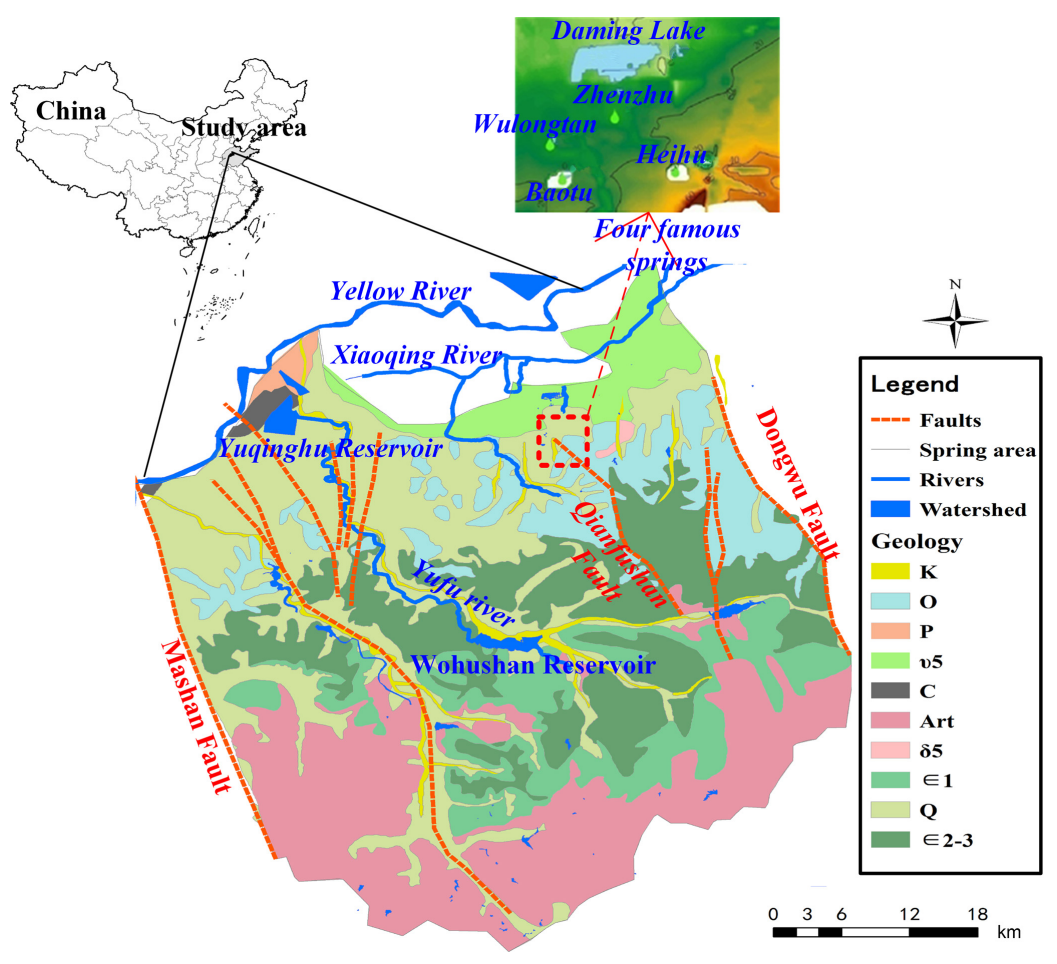

Figure 1. Map of the study area.

groundwater table, the drying up of springs, and the degradation of groundwater quality.

Since 1972, springs in Jinan have suffered from drying up. The longest duration for drying up of the Baotu Spring was approximately 926 days at the beginning of the 21 st century. Since 1981, much research has been carried out to study the recharges and discharges of the groundwater system in Jinan. Since 2001, a series of measures have been implemented by the Jinan government to restore the flow rate of springs to sustain the demand for economic growth. For example, many pumping wells in the spring catchment were closed, especially in the urban district; groundwater usage was partially replaced by the Yellow River water and the Yangtze River water, and the infiltration of surface water and rains were added (Xi et al., 1987; Cai et al., 2015). The springs started to regush from 2003 and have continued gushing until now. Since 2015, the Sponge City Construction Project has been another important measure put forward by the local government. However, the threat of springs drying up still exists, and the groundwater level is still in a lower position. How to keep the springs gushing perennially and maintain a virtuous circle of water environment in the spring catchment is still the focus of the society.

Considering the dynamic changes in the spring flow and its influence factors in the Jinan spring catchment, this paper will analyze the changes in the spring flow rate in the most recent 50 years and then discuss the causes of decreases in the spring flow in view of climate change and human activi- ties. An artificial neural network method is employed to represent the relationship among spring flow, precipitation and groundwater use. The results can provide suggestions for the protection of the springs in Jinan city.

\section{Study area}

\subsection{Background}

Covering an area of approximately $1500 \mathrm{~km}^{2}$, the Jinan spring catchment $\left(116^{\circ} 40^{\prime}-117^{\circ} 14^{\prime} \mathrm{E}, 36^{\circ} 28^{\prime}-36^{\circ} 46^{\prime} \mathrm{N}\right)$ is situated in the middle of Jinan, Shandong province, China. The northern boundary of the area is the contact zone of metamorphic and magmatic activity, mainly along the Yellow River and the Xiaoqing River. The southern boundary divides the watershed, and the eastern and western boundaries of the spring catchment are constrained by two water-barrier faults, the Dongwu fault and the Mashan fault, respectively (as shown in Fig. 1). The catchment is a monoclinic structure, ranging in elevation from $700 \mathrm{~m}$ above sea level (m a.s.l.) in the south to $26 \mathrm{~m}$ a.s.l. in the north. The study area has the continental climate of a warm temperate zone. The annual mean precipitation is approximately $670.47 \mathrm{~mm}$, while the annual mean evaporation is approximately $1475.6 \mathrm{~mm}$. More than $70 \%$ of the precipitation falls from June to September, which leads to serious problems of urban waterlogging in $\mathrm{Ji}$ nan city during the season. The average annual temperature is $14.2^{\circ} \mathrm{C}$, and the frost-free period is approximately 192 
238 days. The Yellow River, Xiaoqing River, Yufu River and Beidasha River are the major rivers in the study area.

\subsection{Geology and hydrogeology}

The study area is situated in the transitional zone of the Luzhong Mountains and the piedmont plain. Topographically, the karst aquifer system is complex and diverse and is divided into three areas from south to north: the southern part consists of steep mountains and deep eroded valleys with an absolute elevation of 500-700 m; the central part is a hilly area, with broad valleys and developed gullies with an elevation of $250-500 \mathrm{~m}$; the northern part includes the Yellow River Piedmont and an alluvial plain with an absolute elevation of approximately $20-50 \mathrm{~m}$. The strata exposed in the study area are mostly complete, with Upper Cambrian and Lower-Middle Ordovician limestone as the major aquifers. The basement of the catchment is the Archean Taishan Group, consisting of metamorphic rocks exposed in the south area. The Cambrian strata are well exposed from the south to the north and are characterized by the interbedding of limestone and shale. The Ordovician strata are mostly distributed in the middle of the study area and are composed by thick-bedded limestone. All of the Paleozoic strata are gradually inclined to the north with a dip direction of $20^{\circ} \mathrm{NE}$ and then buried under the Quaternary. The Quaternary is well exposed in the area from the lower Pleistocene to the Holocene. Among them, some faults are widely developed throughout the study area, such as the Mashan fault, Dongwu fault and Qianfoshan fault. The faults with north-west and north-east directions are dominating features, providing possible formations for spring water. Subject to the geology and topography conditions, the southern area has become the indirect recharge area of the spring catchment, the middle part is the direct recharge area and the runoff area, and the northern part is the drainage area where most springs are located.

Based on the topography, lithology, geology and other characteristics, the aquifers in the study area can be divided into four types: pore water in a Quaternary aquifer; fractured karst water in an Ordovician aquifer; karst fissure water in Cambrian aquifers; and fractures water in an Archaean aquifer (Qian et al., 2006). Among them, pore water and karst water are the major groundwater resources in the study area, accounting for more than $80 \%$ of the total groundwater discharge, with the karst aquifer being the major supplier of water resources for springs. The Archaean aquifer only exists in some special formations and contributes little to the springs. This paper mainly analyses the former three types of groundwater aquifers.

\section{Analysis of the spring flow and its influence factors}

Groundwater level is the most fundamental indicator of the status of groundwater. In the Jinan spring catchment, the most important influence factors are precipitation and groundwater abstraction. Other aspects, such as artificial recharge, also affect the dynamics of the Jinan spring flow, but with limited effect. The dynamic changes in precipitation, groundwater abstraction and spring flow will be analyzed below.

\subsection{Recharge items of groundwater}

\subsubsection{Changes in the precipitation}

The annual precipitation in the spring catchment is shown in Fig. 2. It can be seen that the precipitation from 19562013 showed strong variations, i.e., the highest precipitation is $1196.6 \mathrm{~mm}$ in 1964 , while the lowest is just $340 \mathrm{~mm}$ in 1989. There are several significant periods: 1961-1964 and 2003-2005 are the wet years; 1969-1980, 1982-1985, and 2007-2010 are normal years; 1965-1968, 1986-1989 and 1999-2002 are the dry years.

\subsubsection{Other recharge sources to the aquifer}

In addition to precipitation, the infiltration from the Yufu River and the Beidasha River and agricultural irrigation are also important recharge sources of the karst aquifers. However, after reservoirs were built upstream and in branches of the Yufu River and the Beidasha River, the river channels were dry most of the time. Though the artificial recharge in the strong leakage areas causes a short-term increase in groundwater level, the influence is limited and the effect is fugacious. For the agricultural irrigation, the amount is much less than the artificial recharge and thus has much less effect on the rise of groundwater level and the regushing of spring flow. As a consequence, the major recharge item of the karst aquifer is precipitation and is considered an important factor in this paper.

\subsection{Groundwater discharges}

It is evident in Fig. 2 that the spring flow and groundwater abstraction correlated negatively. The spring flow showed a decreasing trend before 2003, while the groundwater abstraction increased gradually. The groundwater abstraction in the urban district increased in the earlier years and then decreased rapidly in 1980 because most of the pumping wells were shut down by the local government for the protection of the springs. These wells have maintained a rate of approximately $10 \times 10^{4} \mathrm{~m}^{3} \mathrm{~d}^{-1}$ until now. As supplements, the groundwater abstraction in suburban areas increased rapidly to meet the demand of the economic development and the requirements of protecting springs. The total groundwater abstraction in the spring catchment also increased sharply and has maintained a rate of approximately $70 \times 10^{4} \mathrm{~m}^{3} \mathrm{~d}^{-1}$ from 2003 until parts of the groundwater supplement were replaced by the Yellow River and the Yangtze River water. 


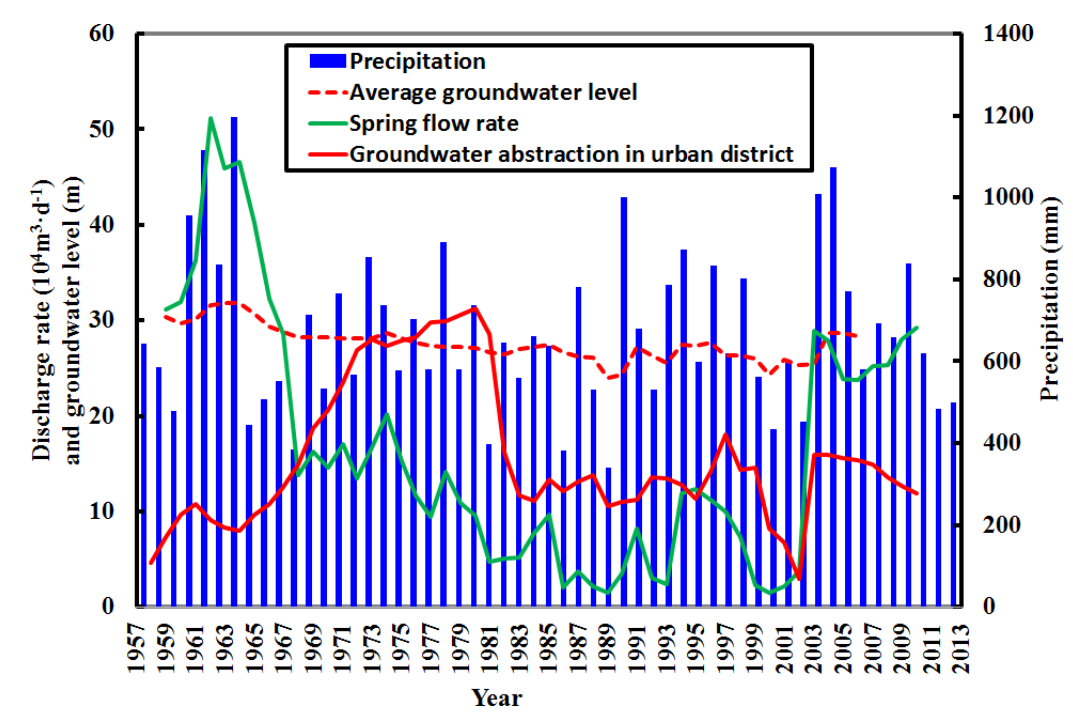

Figure 2. Changes in precipitation, the spring flow rate, groundwater abstraction and groundwater level.

\subsection{Relation between groundwater level and spring flow}

Only when the groundwater level is above the ground surface will springs have the chance to pour out. In other words, spring discharge is strongly affected by groundwater level. It can be seen from Fig. 2 that groundwater level has a similar trend as spring flow. However, spring flow is more sensitive, as it changes faster than groundwater level. A correlation analysis was performed to describe the relation between them. The result shows that groundwater level and spring flow have a very close relation with the correlation coefficient greater than 0.885 .

\subsection{Responses of spring flow changes to human activities}

The changes in the spring flow rate, average groundwater level, groundwater abstraction in the urban district and precipitation are displayed in Fig. 2. It is obvious that spring flow has a positive relation with precipitation and an inverse relation with groundwater abstraction. To further analyze the characteristics of spring flow and its response to natural and human activities, the Mann-Kenall (M-K) test and Pettitt change point test were applied ( $\mathrm{Li}$ et al., 2014). The result from the M-K test indicated an increasing trend before 1967 and a decreasing trend after 1968. The change point in the spring flow series was 1980 and was calculated using the Pettitt change point analysis. Based on the statistical analysis, comprehensively considering the human activities and natural conditions, the characteristics of spring discharge were divided into four periods:

1. The natural period (before 1967): There was little groundwater abstraction before 1967. The average spring discharge rate varied from $30 \times 10^{4}$ to $40 \times 10^{4} \mathrm{~m}^{3} \mathrm{~d}^{-1}$. The highest spring flow rate was
$50.18 \times 10^{4} \mathrm{~m}^{3} \mathrm{~d}^{-1}$ in 1962. In addition, the spring flow varied similarly to the trend of precipitation. In this period, precipitation was the major influence factor of spring flow, as the coefficient parameter between them was 0.75 .

2. The period of exploiting groundwater seriously (19681980): since 1965, a large number of pumping wells have been drilled in the spring discharge area. The rate of groundwater abstraction in the urban district increased from $10 \times 10^{4}$ to $30 \times 10^{4} \mathrm{~m}^{3} \mathrm{~d}^{-1}$ in the first five years. The rate of total groundwater abstraction in the Jinan spring catchment reached $60 \times 10^{4} \mathrm{~m}^{3} \mathrm{~d}^{-1}$ in 1972 , and then increased to $70 \times 10^{4} \mathrm{~m}^{3} \mathrm{~d}^{-1}$ by 1980 . As a result of the over-exploitation of groundwater, the springs stopped gushing during the dry seasons since 1972, and the number of dried-up days increased.

3. The period of controlling groundwater use (19812000): in order to protect springs, the Jinan government put forward a series of measures and the most important one was transferring groundwater abstraction in urban areas to suburban areas. The exploitation rate in urban areas (spring discharge areas) decreased suddenly from $30 \times 10^{4}$ to $12 \times 10^{4} \mathrm{~m}^{3} \mathrm{~d}^{-1}$, and the groundwater level was restored gradually. However, the spring flow still decreased gradually, and the number of dried-up days increased, as the spring catchment is a groundwater system.

4. The period of multiwater source use (after 2001): since 2001, water from the Yellow River, the Yangtze River and two reservoirs (i.e., Wohushan Reservoir and Yuqinghu Reservoir) were gradually used jointly in the supply water system, thus reducing much of the abstraction of groundwater. Additionally, the superfluous sur- 
face water was artificially recharged into the groundwater system since 2001. These factors have led to the gushing of springs from September 2003 until now, and the spring flow was recovered gradually.

\section{Relationship among spring flow and influence factors}

The spring flow is strongly affected by natural and human activities, and common models cannot reflect the changes in spring flow very well. To further understand the dynamic changes in spring flow and the relationship among spring flow, precipitation and human activities, an artificial neural network (ANN) model was developed. An ANN model is a nonlinear method inspired by the structure and functions of the human nervous system. ANN is self-adaptive and has high accuracy. ANN has been proven to be an efficient method in powerful computations of complex nonlinear relationships. Back-propagation (BP) neural networks are the most popular ANN models and are widely used (Kurtulus and Razack, 2006; Hu et al., 2008; Li et al., 2012).

The precipitation and exploitation rate of groundwater in the current and previous year were used as the input factors; and the spring flow rate served as the output item. The period from 1960-2007 is taken as the calibration period to train the model, and the period from 2008-2010 is regarded as the verification period to check the model. The result is shown in Fig. 3. The correlation coefficient between the measured and simulated values is 0.99 , which indicates that the ANN model can reflect the changes of spring flow and can be used to predict the spring flow in the Jinan spring catchment.

\section{Concluding remarks}

Karst aquifers play an important role in supplying the drinking water and supporting the economic development of $\mathrm{Ji}$ nan city, and the spring flow is a significant indicator of the changes in the groundwater system and famous landscape. Consequently, analyzing the changes of spring flow and its response to the influence factors is highly necessary for the managers of water resources. The spring flow in the Jinan spring catchment is strongly influenced by precipitation and human activities, such as groundwater abstraction, artificial recharge and water transfer projects. A partial correlation analysis was performed to quantitatively demonstrate its importance. The results showed that the partial correlation coefficient between spring flow rate and precipitation is 0.666 , and the partial correlation coefficient between spring flow rate and the groundwater abstraction in the previous year is -0.259 . This means that $92.5 \%$ of the dynamic changes in the spring flow are affected by precipitation and groundwater abstraction. Precipitation plays a major role in affecting the spring flow.

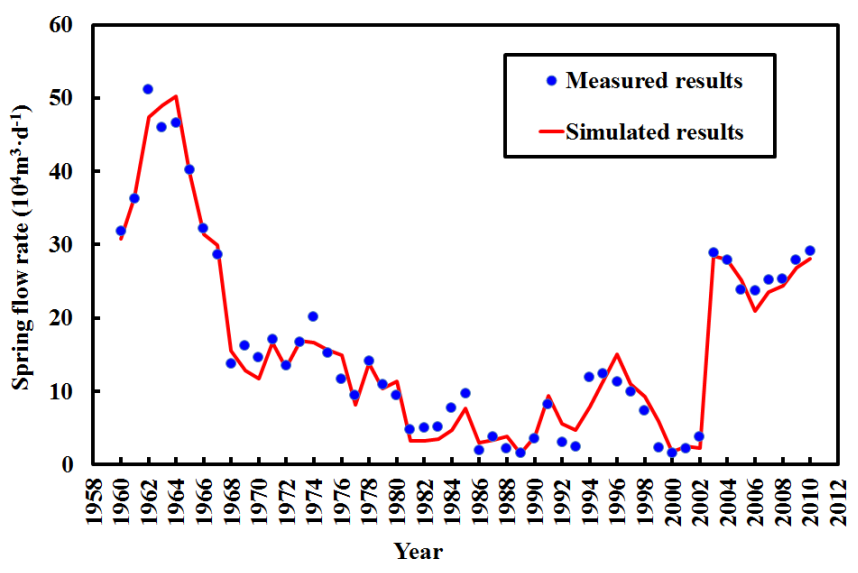

Figure 3. Comparison of measured and simulated spring flow rate.

The characteristics of spring flow were divided into four periods: (1) the natural period; (2) the period of exploiting groundwater seriously; (3) the period of controlling groundwater abstraction; and (4) the period of multiwater source use. After a series of measurements were proposed and implemented by hydrogeologists and the local government in Jinan, the spring flow almost remained in a new dynamic balance. An ANN model was developed to simulate the changes of spring flow, and the good agreement of the results further suggests precipitation and exploitation are the most important influence factors.

Though the groundwater level is recovered to a certain degree and the spring flow has been regushing for more than fourteen years since 2003, the spring flow in Jinan is still threatened by human activities, mainly because the water resources are scarce and an imbalance between water storage and demand exits. Considering the expensive investment for transferring water from an outside catchment in Jinan, the current best suggestion to protect the famous springs in the city is to improve water utilization efficiency and the recycling utilization efficiency, especially the spring water utilization. This paper mainly discusses the changes in spring flow, precipitation, and groundwater abstraction and the relationship among them. The detailed analysis of rational groundwater use and protection of springs will be further studied in the near future.

Data availability. Part of the raw data required to reproduce these findings are available to download from http://jnswj.net/ jsp/sw/jnsw.jsp and http://jnsww.com.cn:9090/jnsw/ (last access: 30 May 2018). Other data are maintained secrecy according to Chinese law and not publicly accessible. The processed data required to reproduce these findings cannot be shared at this time as the data also forms part of an ongoing study. 
Author contributions. XL and KS collected the data. XL and LH analyzed the results. KS developed the ANN model. XL, LH and KS wrote the manuscript.

Competing interests. The authors declare that they have no conflict of interest.

Special issue statement. This article is part of the special issue "Innovative water resources management - understanding and balancing interactions between humankind and nature". It is a result of the 8th International Water Resources Management Conference of ICWRS, Beijing, China, 13-15 June 2018.

Acknowledgements. This study was supported by the National Nature Science Foundation of China (grant number: 41572220). The authors would also like to acknowledge the financial support of the project named Water Cycle and Hydrological Process Modeling of Jinan "Sponge City”.

Edited by: Yangbo Chen

Reviewed by: two anonymous referees

\section{References}

Bakalowicz, M.: Karst groundwater: a challenge for new resources, Hydrogeol. J., 13, 148-160, https://doi.org/10.1007/s10040-0040402-9, 2005.

Cai, Y., Yu, D., Lu, S., Cheng, H., and Wu, D.: The Water Supply Hydrogeology Report of High Quality in Jinan Area (in Chinese), Report, Shandong Provincial Geo-mineral Engineering Exploration Institute, Jinan, China, 223 pp., 2015.

Hartmann, A., Goldscheider, N., Wagener, T., Lange, J., and Weiler, M.: Karst water resources in a changing world: Review of hydrological modeling approaches, Rev. Geophys., 52, 218-242, https://doi.org/10.1002/2013RG000443, 2014.
Hu, C., Hao, Y., Yeh, T.-C. J., Pang, B., and Wu, Z.: Simulation of spring flows from a karst aquifer with an artificial neural network, Hydrol. Process., 22, 596-604, https://doi.org/10.1002/hyp.6625, 2008.

Kang, F., Jin, M., and Qin, P.: Sustainable yield of a karst aquifer system: a case study of Jinan springs in northern China, Hydrogeol. J., 19, 851-863, https://doi.org/10.1007/s10040-011-0725$2,2011$.

Kurtulus, B. and Razack, M.: Evaluation of the ability of an artificial neural network model to simulate the inputoutput responses of a large karstic aquifer: the La Rochefoucauld aquifer (Charente, France), Hydrogeol. J., 15, 241-254, https://doi.org/10.1007/s10040-006-0077-5, 2006.

Li, B., Yu, Z., Liang, Z., Song, K., Li, H., Wang, Y., Zhang, W., and Acharya, K.: Effects of Climate Variations and Human Activities on Runoff in the Zoige Alpine Wetland in the Eastern Edge of the Tibetan Plateau, J. Hydrol. Eng., 19, 1026-1035, 2014.

Li, X., Shu, L., Liu, L., Yin, D., and Wen, J.: Sensitivity analysis of groundwater level in Jinci Spring Basin (China) based on artificial neural network modeling, Hydrogeol. J., 20, 727-738, https://doi.org/10.1007/s10040-012-0843-5, 2012.

Ma, T., Wang, Y., and Guo, Q.: Response of carbonate aquifer to climate change in northern China: a case study at the Shentou karst springs, J. Hydrol., 297, 274-284, https://doi.org/10.1016/j.jhydrol.2004.04.020, 2004.

Qian, J., Zhan, H., Wu, Y., Li, F., and Wang, J.: Fractured-karst spring-flow protections: a case study in Jinan, China, Hydrogeol. J., 14, 1192, https://doi.org/10.1007/s10040-006-0061-0, 2006.

Vries, J. J. D. and Simmers, I.: Groundwater recharge: an overview of processes and challenges, Hydrogeol. J., 10, 5-17, 2002.

Xi, D., Cao, Y., Li, Z., Fang, P., Shao, Z., and Jia, G.: The Water Supply Hydrogeology Exploitation Report in Jinan City, Shandong Province (in Chinese), Report, Shandong Provincial Geomineral Engineering Exploration Institute, Jinan, China, 165 pp., 1987. 